\title{
Sosyal Hizmet Uygulamasında Din ve Maneviyatın Rolü ile Manevi Yönelim arasındaki İlişkinin İncelenmesi
}

DOI: $10.26466 /$ opus.658418

\section{Muhammet Cevat Acar* - Hidir Apak**}

* Dr. Öğretim Üyesi, Mardin Artuklu Üniversitesi, Eebiyat Fakütesi Psikoloji Böl., Mardin/Türkiye E-Posta: mcacar@artuklu.edu.tr

ORCID: $\quad 0000-0002-4222-3101$

** Dr. Öğretim Üyesi, Mardin Artuklu Üniversitesi, Sağlık Bilimleri Fakültesi, Mardin/Türkiye E-Posta: hidirapak@hotmail.com

ORCID: $0000-0002-2330-3093$

\section{Öz}

Bu araştırmanın amacl, sosyal hizmet bölümü öğrencilerinin maneviyat düzeylerinin ve sosyal hizmet uygulamasında din ve maneviyatın rolüne ilişskin görüşlerinin belirlenmesi ve cinsiyet ile sınf düzeyi değişkenlerine göre farklılaşıp farklılaşmadığının ortaya konulmasıdır. Araştırmanın bir diğer amacı da sosyal hizmet bölümü öğrencilerinin maneviyat düzeylerinin sosyal hizmet uygulamasında din ve maneviyatın rolüne ilişkin görüşlerini etkileyip etkilemediğini belirlemektir. Araştırmanın amaçları doğrultusunda 242 öğrenciye Kasapoğlu tarafindan geliştirilen Manevi Yönelim Ölçeği ile Sheridan tarafindan geliştirilip Apak tarafindan Türkçeye uyarlanan Sosyal Hizmet Uygulamasinda Din ve Maneviyatın Rolü Ölçeği uygulanmış ve elde edilen veriler $t$ testi ve basit doğrusal regresyon ile analiz edilmiştir. Yapılan analizler sonucunda öğrencilerin manevi yönelim düzeylerinin ve sosyal hizmet uygulamasında din ve maneviyatın rolüne ilişkin olumlu bakış açılarının yüksek olduğu belirlenmiştir. Cinsiyet ve sinıf düzeyi değişkenlerinin öğrencilerin manevi yönelim düzeyleri üzerinde anlamlı bir farklılaşmaya yol açtığ ; ancak sosyal hizmet uygulamasında din ve maneviyatın rolüne ilişkin görüşleri açısından anlamlı bir farklılaşmaya yol açmadığı belirlenmiştir.

Anahtar Kelimeler: Maneviyat, Manevi yönelim, Sosyal hizmet, Üniversite öğrencileri 


\title{
Investigating Relationship between Role of Religion and Spirituality in Social Work Practice and Spiritual Orientation Levels of The Social Work Students
}

\begin{abstract}
The aim of this study is to determine the spirituality levels of social work students and their views on the role of religion and spirituality in social work practice and to determine whether they differ according to gender and grade level variables. Another aim of the study is to determine whether the spirituality levels of social work students affect their views on the role of religion and spirituality in social work practice. For the purposes of the study, 242 students were administered the Spiritual Orientation Scale developed by Kasapoğlu and the Role of Religion and Spirituality in Social Work Practice developed by Sheridan and adapted to Turkish by Apak and the data obtained were analyzed by $t$ test and simple linear regression. As a result of the analyzes, it was determined that the students' level of spiritual orientation and positive views about the role of religion and spirituality in social work practice were high. Gender and grade level variables lead to a significant difference on the spiritual orientation levels of the students; however, it did not lead to a significant difference in terms of their views on the role of religion and spirituality in social work practice.
\end{abstract}

Keywords: Spirituality, spiritual orientation, social work, university students 


\section{Giriş}

Sosyal hizmet, kendine ait bilimsel teorileri ve yaklaşımları olması açısından uygulamalı bir bilim dalı ve akademik bir disiplin olarak kabul edilmektedir. Bu bakımdan, özü itibariyle sosyal hizmeti; bilim, eğitim ve uygulama olarak üç parçada düşünmek olanaklıdır. Bütünü oluşturan bu parçaların birbirini beslemesi gerektiği düşünülmektedir (Çağlar, 2012, s.46). Eğitim, bu parçaların içinde hem bilim dalı hem de uygulama alanını doğrudan ilgilendiren ve etkileyen bir parçadır. Sosyal hizmet eğitimi, sosyal hizmetin bir meslek ve akademik disiplin olarak ortaya çıkışının en belirgin başlangıç noktasıdır. Bu sıfır noktası, o zamana kadar din ve hayırseverlik yaklaşımlarıyla ele alınan hizmetlerde eğitimli elemanlara ihtiyaç duyulması ile olmuştur. Bu ihtiyacın gerçekleşmesinde atılan adımlar sonucunda, 1899' da Amsterdam'da, ilk sosyal hizmet okulu açılmıştır (Kut, 1991).

Sosyal hizmet eğitimi hem bilimselliği hem de toplumsal özellikleri içerisine alan bir yapıya sahiptir. Toplumsal olarak mesleğin, uygulanacağı kültüre ve özelliklere göre şekillenmesi gerektiği ifade edilebilir. Bu durumda eğitimin temel görevlerinden biri öğrencileri kültürel olarak hassas ve farkl1lıklara saygı duyan bir göreve hazırlamaktır.

Maneviyat ve din bütün kültürlerde önemli bir rol sahibi olduğundan, sosyal çalışmacı adayları olan öğrencilerin din ve maneviyatın insan hayatı üzerindeki etkisini anlamaları gereklidir. Böylelikle öğrencilerin ileride sahip olacakları meslek ile müracaatçılarının dini inançları ve değerler sisteminden haberdar olabilmeleri sağlanacaktır (Zastrow ve Kirst-Ashman, 2015, s.324). Sosyal hizmet eğitiminin temel ilkelerinden biri bu noktada, farklı manevi bakış açları ve çeşitli dini inançları içermesidir (Stewart ve Koeske, 2006). "Maneviyat" terimi sosyal hizmet literatüründe, insanların anlam, amaç ve ahlak çerçevelerini geliştirdikleri hem dini hem de dini olmayan yolları içermek için yaygın olarak kullanılmaktadır (Canda ve Furman, 2010; Vetvik, Danbolt, Furman, Benson ve Canda, 2018). Ayrica maneviyat, sosyal hizmet uygulamalarında sıklıkla kullanılan güçlendirme, ekosistem, kültürel duyarlılık ve bütüncül yaklaşımla da ilişkili bir kavramdır (Tatlıcıoğlu ve Kılıç, 2019).

Modern çağla birlikte insanlar bir anlam arayışına girmiş ve hayatlarını yeniden düzenleme arzusunu yaşamaya başlamışlardır. Bu arzuyu pozitivist ve materyalist paradigmaların doyuramaması ise insanları maneviyata 
yöneltmiştir. Günümüz insanı artık manevi duyguları yaşamanın gerekliliğini kavramış ve bu ihtiyacı gidermenin yollarını aramaya başlamıştır. Bu arayış hayatın her alanında olduğu gibi tıp, psikoloji ve sosyal hizmet gibi yardım mesleklerinde de kendini hissettirmektedir.

Sperry ve Shafranske (2009, s.3) maneviyat kavramının İngilizcedeki en yanlış anlaşılmış kavramlardan biri olduğunu belirtmektedirler. Maneviyatın çoğu zaman mistik deneyimlerle, metafizik dünyayla, dinle, Yeni Çağ inanışlarıyla ve ibadet, meditasyon gibi belirgin bazı aktivitelerle açıklandığı görülmektedir. Ama aslında maneviyat tüm bu açıklama ve tanımlamaların ötesindedir ve bunların temelini oluşturan bir fenomendir. Nitekim Martin (2007, s.97) de maneviyatı bütün erdemlerle ilişkili bir boyut olarak da tanımlamaktadır. Ancak maneviyatı bu kadar temel ve kapsayıc gören yaklaşımların yanında maneviyatın karakter güçlerinden biri olduğunu ve hatta bu güçlerden aşkınlığın bir alt boyutu olarak bile görülebileceğini belirten araştırmacılar da bulunmaktadır (Peterson ve Seligman, 2004).

Maneviyata duyarlı psikolojik yardım türlerinin her geçen gün arttığı (Kaya ve Ekşi, 2016), aile danışmanlığı vb. alanlarda manevi yönelimli yardım türlerinin (Ağırbaş, 2017) kullanılmaya başlandığı günümüzde sosyal hizmetler alanında da maneviyatın nerede durduğuna ilişkin çalışmalar yapılmaktadır (Apak, 2018a). Bu gelişmeler, maneviyatın ve manevi yönelimin tanımlanmasını ve sınırlarının belirlenmesini gerekli kılmaktadır. Nitekim maneviyatın bireysel ve toplumsal hayattaki tezahürleri ve din ile olan ilişkisi de bu kavramın yardım mesleklerinde nerede duracağı konusunda belirleyici bir faktördür.

Genel anlamda maneviyat tanımlarına bakıldığında maneviyatın Tanrı ve/veya kutsal olan ile bir uyum arama süreci olduğu söylenebilir (Richards ve Bergin, 2011, s. 22). Bu uyum sürecinin aslında fiziksel bir varlık olan insanoğlunun aşkın bir gerçekliğin içinde var olduğu ve bu aşkınlığa olan inancını ifade ettiği görülmektedir (Ekşi, Kaya ve Çiftçi, 2016, s. 15). İnsanın sahip olduğu bu inanç onu aşkın olan ile deneyimler yaşamaya götürmektedir ve aslında maneviyatın temelini bu deneyimler oluşturmaktadır (Özdoğan, 2007, s.17).

ABD'de eğitim politikası ve akreditasyon standartları belirlemede yetkili kuruluş olan Sosyal Hizmet Eğitimi Konseyi (CSWE) 1994 yılındaki müfredat politika ifadesi, farklı sosyal, kültürel, ırksal, dinî, manevi ve sınıf temelli müracaatçılara yaklaşım ve becerilerin, uygulama içeriğinde son derece 
önemli olduğunu belirtmektedir. Bu dönemde CSWE, sosyal hizmet eğitimi müfredat politika ilkelerinde dinî ve manevi çeşitliliği tanıyan konular eklenmesini gerekli bulmuştur (Canda, 1999). Sosyal Hizmet Eğitim Konseyi'nin 'Eğitim Politikası ve Denklik Standardı' artık onaylı lisans ve lisansüstü programlarının bu alanlarda içeriğe sahip olmasını ve böylece öğrencilerin farklı dinî geçmişlerden gelen müracaatçlarla birlikte yaklaşımlar geliştirmesini ve çalışma becerisine sahip olmasını zorunlu tutmaktadır (Zastrow, 2013, s.152). Buna benzer olarak 2017 yılında revize edilen NASW (National Association of Social Workers) Etik Kuralları'na göre, sosyal çalışmacılar, müracaatçıların kültürlerine ve dinsel çeşitliliğine duyarlı olmalı, bu çeşitliliği tanımak ve anlamak için eğitim almalı (Yeşilkayalı, 2018) ibaresi de önemlidir.

CSWE akreditasyon standartları ve NASW etik ilkeleri gösteriyor ki, ayrımcı olmayan sosyal hizmet uygulamalarını teşvik etmek için din ve maneviyat müfredatın içeriğine dâhil edilmelidir. Bu durum başta $\mathrm{ABD}$ olmak üzere birçok ülkede maneviyatın ve dinin sosyal hizmet eğitimine entegre edilmesinin gerekliliğini gündeme getirmiştir. Maneviyat ve sosyal hizmet alanında çalışan ve çoğunluğunu ABD ve Avrupalıların oluşturduğu bazı sosyal hizmet akademisyenleri; sosyal çalışmacıların müracaatçılarla daha etkin çalışma yürütmesi için manevi anlamda hazırlıklı olmaları gerektiğini belirtmişlerdir. Ayrıca bu akademisyenler, sosyal hizmet müfredatına maneviyat ile ilgili derslerin dâhil edilmesini savunmaktadırlar (Apak, 2018a; Canda ve Furman, 2010; Gilligan ve Furness, 2005; Streets, 2009; Sheridan, Wilmer ve Atcheson, 1994). Street'in (2009) de bahsettiği gibi dinî veya manevi konuları sosyal hizmet müfredatına yerleştirmek; dine destek vermek anlamına gelmemektedir. Fakat denilebilir ki, böyle bir düşüncenin gündeme gelmiş olması; maneviyatın birey ve topluluklar üzerinde oldukça etkili olmasından kaynaklanmış olabilir. Ayrıca, kişinin maneviyatı anlamak için böyle bir kimlik sahibi veya din adamı olmasının gerekmediği de belirtilmelidir. Maneviyatı anlamak ve araştırmak için bireyin istekli olması yeterli bir şarttır (Wagler-Martin, 2007, s.138).

Sosyal hizmet eğitimi, uygulaması ve araştırması gereği maneviyata olan ilgiyi artırmak için yeni bilgiler edinmeyi sağlamaktadır. Bu bilgiler, sosyal hizmet çalışanlarının insanları anlama yeteneğini geliştirmekte ve insanların ihtiyaçlarını nasıl daha iyi karşılarım sorusuna yanıt buldurmaktadır (Streets, 2009). Bu sorular ise birçok müracaatçıların önemli derecede yönelim 
gösterdiği sorulardır. Sosyal hizmet eğitiminde maneviyat ve dini inancın yer bulması müracaatçların manevi gereksinimlerinin belirlenip bu gereksinimlerin karşılanmasına yönelik sosyal hizmet öğrencilerini mesleğe hazırlamada önemli rol oynayabilmektedir. Müracaatçlara bütüncül yaklaşımda manevi duyguların ve buna bağlı olarak hizmet sunmanın manevi boyutunun önemi göz ardı edilmemelidir. Günümüzde; kürtaj, doğum kontrol yöntemlerinin kullanılması, eşcinsellerin durumu, klonlama, yeniden üretim teknolojisi, kadınların rolü, devlet okullarında ibadet ve ötenazi gibi birçok toplumsal meselenin dinî ve manevi boyutu vardır (Zastrow, 2013, s.152). Sosyal çalışmacıların dinî ve manevi yönelimli müracaatçlarla birlikte verimli uygulamalarda bulunabilmesi için bu konuda eğitimli olmalarının gerekliliği artmaktadır.

Birçok ülkede maneviyatın ve dinin sosyal hizmet eğitimine entegre edilmesinin gerekliliği Türkiye'de de tartışlan bir konu haline gelmiştir. Esasından manevi destek, yüzyıllardır toplumun kültüründe ve değer kodlarında mevcut, yaygın bir uygulaması da olan bir destek türüdür. Ancak son yıllarda manevi desteğin teorik ve kurumsal boyutları ön plana çıkmaktadır (Kesgin, 2019, s.2). Bununla birlikte ülkemizde sosyal hizmet okullar1nın müfredatlarında yaşadığımız kültürü yakından inceleyen dersler azınlıktadır. İçinde yaşadığımız kültürün insanı anlamada önemli olduğu düşünüldüğ̈̈nde bu konu sosyal hizmet lisans programlarının bir eksiği olarak görünmektedir. $\mathrm{Bu}$ eksiklikten maneviyat ve din de nasibini almıştır. $\mathrm{Bu}$ bakımdan ifade edebilir ki, Türkiye'de sosyal hizmet açısından maneviyat, gerekli ilgiyi görememiş ve dolayısıyla manevi konular, sosyal hizmet eğitiminde pek de yer bulamamıştır. Her ne kadar sosyal hizmet manevi ve dini çeşitlilik farklılıklara bağlı olması gerekliliği gündeme getirilse de, eğitimimizde bu konulardaki içeriğin eksik olması göze çarpmaktadır. Türkiye'de sosyal hizmet bölümü müfredatlarının araştırıldığı bir çalışmada bölümlerin \%80'inde maneviyatla ilgili bir dersin olmadı̆̆ tespit edilmiştir (Apak, 2018a). Bu nedenle sosyal çalışmacıların büyük bir çoğunluğunun müracaatçlarının uygulamadaki dinine ve maneviyata ilişkin bir değerlendirme veya dikkatin dâhil edilmesine ilişkin özel bir eğitim içeriği almamaktadır. Bu nedenle bu çalışma maneviyatla ilgili ders alan ve almayan öğrencilerin hem sosyal çalışma pratiğinin hem de profesyonel büyümenin bir parçası olarak maneviyat görüşlerine odaklanmaktadır. 
Maneviyat ve sosyal hizmet uygulamaları arasındaki arayüz hakkında çok şey yazılmakta ve tartı̧malar devam etmektedir (Seinfeld, 2012). Literatürde maneviyata duyarlı sosyal hizmete ilişkin çalışmaların sosyal çalışmacllar (Derezotes, 1995; Lee ve Barrett, 2007; Vetvik, vd., 2018; Rinkel, Larsen, Harrington ve Chun, 2018), sosyal hizmet öğretim elemanları (Dudley ve Helfgott, 1990; Sheridan, vd., 1994) ve sosyal hizmet öğrencilerinin perspektifinden (Bethel, 2004; Bhagwan, 2010; Gilligan ve Furness, 2005; Graff, 2007; Pandya, 2018; Prior ve Quinn, 2012; Stewart ve Koeske, 2006) ele alındığı araştırmalar bulunmaktadır

Maneviyat ve dinin sosyal hizmet pratiğine uygunluğuna odaklanan büyüyen sosyal hizmet literatüründe sosyal çalışmacıların maneviyata duyarlı sosyal hizmete ilişkin deneyimleri, tutumları ve davranışlarıyla ilgili yapılan çalışmaların sayısı daha fazla, bu alandaki öğrencilerin görüşleri, deneyimleri ve beklentileri ile ilgili çalışmaların sayısı daha da azdır. Benzer şekilde, yapılan çalışmalarda bazı coğrafi bölgeler araştıılmış olsa da farklı bölgelerdeki popülasyonlardaki benzersiz demografik özellikleri doğrudan araştırılmamıştır. Ülkelerin içerisinde yaşayan bireylerin din ve maneviyatla ilgili farklı görüşleri olması, öğrencilerin görüşleri üzerinde bir etkisi olabilmektedir. Ayrıca, ırk ve etnik köken gibi farklı faktörlerin, sosyal hizmet uygulamalarında öğrencinin dine ve maneviyata yönelik tutumlarını nasıl etkilediği konusunda çok az şey bilinmektedir. Bu düşünceden hareketle yapılan çalışmanın amacı, Türkiye'de lisans düzeyindeki sosyal hizmet bölümü öğrencilerinin sosyal hizmet uygulamalarında dinin ve maneviyatın rolüne ilişkin görüşleri, tutumları ve manevi yönelim düzeylerini ortaya koyma şeklinde belirlenmiştir. Ayrıca araştırmada, sosyal hizmet öğrencilerinin kişisel maneviyatlarını ve inançlarını anlamanın gelecekteki uygulayıcılar olarak davranışlarını önemli ölçüde etkileyebileceği düşüncesinden (Sheridan ve Amato-von Hemert, 1999) hareketle, öğrencilerin sosyal hizmet uygulamalarında maneviyat ve din kullanımındaki algıları ve manevi yönelimleri ile bazı sosyo-demografik veriler arasındaki ilişkiye de odaklanılmıştır. 


\section{Yöntem}

\section{Araştırmanın Modeli}

$\mathrm{Bu}$ araştırma, nicel araştırma yöntemlerinden ilişkisel tarama modeli ile yürütülmüştür. İlişkisel tarama modeli, iki veya daha çok değişken arasında değişimin varlı̆̆ını ve derecesini belirmek amacıyla kullanılan bir modeldir. $\mathrm{Bu}$ modelde çoğunlukla korelasyon analizleri kullanılmaktadır (Karasar, 2010, s.81).

\section{Evren ve Örneklem}

Bu araştırmanın evrenini 2018-2019 bahar yarıyllı eğitim- öğretim yılında Bingöl Üniversitesi Sosyal Hizmet Bölümünde öğrenim gören 3. ve 4. sınıf öğrencisi 373 kişi oluşturmaktadır. Araştırma da örneklem seçimine gidilmeyip Bingöl Üniversitesi Sosyal Hizmet Bölümü'nde öğrenim gören öğrencilerinden ankete katılmaya gönüllü olan tüm öğrencilere ulaşılmaya çalışılmıştır. Araştırmanın örneklemi, evrenin tümüne ulaşma hedefi olduğundan olasılığa dayalı olmayan örnekleme yöntemi kullanılarak belirlenmiştir. Araştırmanın örneklemini 373 öğrenci arasından 242 (kadın= 106, erkek=136) öğrenci oluşturmaktadır.

\section{Veri Toplama Araçları}

Manevi Yönelim Ölçeği (MYÖ): Kasapoğlu (2015) tarafından geliştirilen öğrencilerin manevi yönelimlerini analiz etmek için kullanılmıştır. Ölçek yedili likert tipinde tek boyuttan ve 16 maddeden oluşmaktadır. Ölçekten alınan puanın yüksek olması manevi yönelimin yüksek olduğuna işaret etmektedir. Ölçekte yapılan yapı geçerliği çalışmaları için açıklayıcı ve doğrulayıcı faktör analizi teknikleri kullanılmıştır. Ölçeğin güvenilirliğini değerlendirmek için Cronbach Alpha güvenirlik katsayısı hesaplanmış ve test tekrar test güvenirlik katsayısının .84 olduğu bulunmuştur. Bu araştırmada ise manevi yönelim ölçeğinin Cronbach Alpha değeri 97 olarak bulunmuştur.

Sosyal Hizmet Uygulamasinda Din ve Maneviyatın Rolü (SHUDMR) Ölçeği: Sheridan (2000) tarafından geliştirilen bu ölçek Apak (2018b) tarafından Türkçeye uyarlanmıştır. Ölçeğin amacı, sosyal hizmet uygulamasın- 
da dinin veya maneviyatın rolü hakkındaki katılımcların görüşlerini saptamaya çalışmaktadır. Ölçek beşli likert tipinde tek boyuttan ve 13 maddeden oluşmaktadır. Ölçek geliştirme sürecinde açımlayıcı ve doğrulayıcı faktör analizi çalışmaları yapılmıştır. Ölçeğin Cronbach Alpha katsayısı .82 olarak hesaplanmıştır. Bu çalışmada da SHUDMR Ölçeğinin Cronbach Alpha değeri .91 olarak hesaplanmıştır.

\section{Verilerin Toplanması ve Analizi}

Araştırmada kullanılan ölçeklerin izinleri araştırmacılar tarafından, ölçeği geliştiren ve uyarlayan araştırmacılardan alınmıştır. Hazırlanan soru formu için Bingöl Üniversitesi Etik İlkeleri ve Etik Kurul Başkanlığından (15.04.2019 tarih ve 2019/1-3 sayılı karar) gerekli izin alınmıştır.

2018-2019 eğitim-öğretim yılının bahar döneminde uygulama gerçekleştirilerek veriler toplanmıştır. Veri toplama aşamasında, katılımcılar soru kâğıdına iliştirilmiş bilgilendirilmiş onam aracilığıyla araştırmanın amacı ve kapsamı, süreç ve araştırmacılar hakkında bilgilendirilmiştir. Verilerin çözümlenmesi için SPSS paket programı kullanılmıştır. Analizde, t Testi ve Basit Doğrusal Regresyon kullanılmıştır.

\section{Bulgular}

Bu bölümde, sosyal hizmet öğrencilerinin Manevi Yönelim Ölçeği ile Sosyal Hizmet Uygulamasında Din ve Maneviyatın Rolü (SHUDMR) Ölçeği puanlarına ilişkin veriler değerlendirilmiştir. Öncelikle katılımcıların bu iki ölçekten aldıkları puanlara ilişkin veriler sunulmuştur. Ardında Manevi Yönelim ile SHUDMR değişkenlerinin cinsiyet ve sınıf değişkenlerine göre farklılaşıp farklılaşmadığına dair $t$ testi sonuçları verilmiştir. Son olarak ise manevi yönelim ve SHUDMR ilişkisini ortaya koymak için korelasyon ve manevi yönelimin SHUDMR düzeyini açıklama gücünü ortaya koymak amaciyla yapılan regresyon analizi sonuçları ortaya konulmuştur.

Tablo 1.Manevi Yönelim ve SHUDMR Düzeyleri

\begin{tabular}{llll}
\hline & n & x & ss \\
\hline Manevi Yönelim & 242 & 89,35 & 9,43 \\
SHUDMR & 242 & 52,63 & 20,73 \\
\hline
\end{tabular}


Sosyal hizmet bölümü öğrencilerinin manevi yönelim düzeyleri incelendiğinde öğrencilerinin ortalama puanın üzerinde puan $(x=89,35)$ aldıkları görülmektedir. Manevi yönelim ölçeğinden alınabilecek en düşük puanın 16; en yüksek puanın 112 olduğu göz önünde bulundurulduğunda sosyal hizmet öğrencilerinin manevi yönelim düzeylerinin oldukça yüksek olduğu söylenebilir. Benzer bir durum sosyal hizmet uygulamasında din ve maneviyatın rolünde de görülmektedir. SHUDMR ölçeğinden alınabilecek en düşük puan 13; en yüksek puan ise 65'tir. Sosyal hizmet öğrencilerinin bu ölçekten aldıkları ortalama puan 52,63 olarak bulgulanmıştır. Bu bulgu sosyal hizmet bölümü öğrencilerinin, sosyal hizmet uygulamasında din ve maneviyatın önemli bir rolü olduğu görüşüne sahip olduklarını göstermektedir.

Tablo 2. Cinsiyet Değişkeni Açısından Manevi Yönelim ve SHUDMR

\begin{tabular}{lllllll}
\hline & Cinsiyet & $\mathbf{N}$ & $\mathbf{X}$ & Sd. & F & \multirow{2}{*}{ Sig } \\
\hline \multirow{2}{*}{ SHUDMR } & Kadın & 106 & 52,2 & 8,91 & \multirow{2}{*}{, 071} & \multirow{2}{*}{, 791} \\
& Erkek & 136 & 52,97 & 9,84 & \multirow{2}{*}{017} \\
\hline \multirow{2}{*}{ Manevi Yönelim } & Kadın & 106 & 83,34 & 21,65 & \multirow{2}{*}{5,733} & \multirow{2}{*}{017} \\
& Erkek & 136 & 94,04 & 18,77 & & \\
\hline
\end{tabular}

Tablo-2'ye bakıldığında cinsiyet değişkeninin sosyal hizmet bölümü öğrencilerinin SHUDMR puanların anlamlı düzeyde etkilemediği görülmektedir ( $p>, 05)$. Yani sosyal hizmet bölümünde okuyan erkek ve kadın öğrencilerin sosyal hizmet uygulamasında din ve maneviyatın rolüne ilişkin görüşleri anlamlı bir farklılaşma oluşturmamaktadır. Ancak; manevi yönelim düzeyi açısından cinsiyet değişkeninin anlamlı bir farklılaşmaya yol açtığı görülmektedir $(p<, 05)$. Analiz sonuçlarına göre sosyal hizmet bölümünde okuyan erkek öğrencilerin manevi yönelim düzeyleri, kız öğrencilerden anlamlı olarak daha yüksektir.

Tablo 3. Sınıf Değişkeni ve 'Sosyal Hizmet ve Maneviyat' Dersi Değişkenleri Açısından Manevi Yönelim ve SHUDMR

\begin{tabular}{|c|c|c|c|c|c|c|}
\hline & Sinif & $\mathbf{N}$ & $X$ & Sd. & $\mathbf{F}$ & Sig \\
\hline \multirow{2}{*}{ SHUDMR } & 3. Sinif & 102 & 50,26 & 10,52 & \multirow{2}{*}{,864 } & \multirow{2}{*}{,354 } \\
\hline & 4. Sinif & 140 & 54,36 & 8,16 & & \\
\hline \multirow{2}{*}{ Manevi Yönelim } & 3. Sinif & 102 & 92,3 & 16,69 & \multirow{2}{*}{20,673} & \multirow{2}{*}{,000 } \\
\hline & 4. Sinif & 140 & 87,21 & 23,06 & & \\
\hline
\end{tabular}


Tablo-3'te görüldüğü üzere sınıf değişkeni, sosyal hizmet bölümü öğrencilerinin sosyal hizmet uygulamasında din ve maneviyatın rolüne ilişkin görüşlerinde anlamlı bir farklılaşmaya $(p>, 05)$ yol açmamıştır. Bu durum sosyal hizmet bölümünde okuyan tüm öğrencilerin kişisel maneviyatlarından bağımsız olarak sosyal hizmet uygulamalarında maneviyata duyarlı bir bakış açısına sahip olduklarını gösteriyor olabilir. Ancak manevi yönelim değişkeni açısından sosyal hizmet bölümü öğrencilerinin sınıf düzeyleri anlamlı bir farklılaşma oluşturmaktadır; 3 . Sınıf öğrencilerinin manevi yöne$\lim$ düzeyleri, 4 . Sınıf öğrencilerinden anlamlı derecede $(\mathrm{p}<, 01)$ daha yüksektir. 4. Sınıf öğrencilerinin aynı zamanda Maneviyat ve Sosyal Hizmet dersini almış oldukları göz önünde bulundurulduğunda, bu dersi almış olmanın öğrencilerin SHUDMR düzeylerini yükselttiği ancak bu değişikliğin anlamlı olmadığı görülmektedir. Manevi yönelim ile SHUDMR düzeylerinde farklı sonuçların çıkmasının, ölçeklerin kapsamlarının farklı olması ile ilgili olduğu düşünülmektedir. Nitekim, Manevi Yönelim Ölçeği bireylerin genel maneviyat durumlarını ölçerken; SHUDMR Ölçeği profesyonel hizmet sunma anında maneviyat duyarlılı̆̆ını ölçmektedir.

Tablo 4. Manevi Yönelimin SHUDMR'ye Etkisine İlişkin Regresyon Analizi

\begin{tabular}{lllll}
\hline & B & T & p & R2 \\
\hline Manevi Yönelim &, 17 & 6,243 &, 000 &, 140 \\
\hline
\end{tabular}

Yapılan analiz sonucunda manevi yönelimin sosyal hizmet uygulamasında din ve maneviyatın rolündeki varyansın \% 14 oranında açıkladığı görülmüş̧ür. Manevi yönelim, sosyal hizmet uygulamasında maneviyatın rolünü anlamlı düzeyde $(B=, 17 ; \mathrm{p}<, 01)$ açıklamaktadır. Bu sonuca göre sosyal hizmet bölümü öğrencilerinin manevi yönelim düzeyleri arttıkça sosyal hizmet uygulamasında din ve maneviyatın rolüne ilişkin olumlu görüşleri artacaktır.

\section{Tartışma, Sonuç ve Öneriler}

Sosyal hizmet bölümü öğrencilerinin manevi yönelim düzeyleri incelendiğinde öğrencilerin manevi yönelim düzeylerinin oldukça yüksek olduğu söylenebilir. Bu bulgu birçok araştırma ile paralellik göstermektedir (Bhagwan, 2010; Kaplan ve Dziegielewski, 1999; Stewart ve Koeske, 2006). 
Dini ve manevi inançlar, bazı bireylerin hayatında önemli roller oynamaktadır. Giderek artan bir şekilde, eğitim programları manevi ve dini çeşitliliğe dikkat çekmektedir. Ayrıca bu durum çeşitli inanç sistemlerine saygı duymayı teşvik etmekte ve öğrencilere dini ve manevi çeşitlilik hakkındaki bilgilerini genişletme firsatı sunmaktadır. Kane ve Jacobs (2010) sosyal hizmet öğrencilerinin olduğu 204 öğrenci ile yaptıkları çalışmada üniversite öğrencileri arasında manevi ve dini inançların önemini belirlemişlerdir. Katılımc1lar dini/manevi inançların kendileri için önemli olduğunu, dini/manevi inançların zor durumlarla başa çıkmalarını sağladığını dini/manevi inançları nedeniyle daha iyi insanlar olduklarını tespit etmişlerdir.

Maneviyat, sosyal hizmet uygulamasında; sosyal çalışmacıları motive eden, zorluklarla baş etmelerini sağlayan bir argüman olabilmektedir. Sosyal çalışmacilar hemen hemen her gün, adaletsizlikten, ayrımcilıktan ve şiddetten zarar görmüş dezavantajı bireyler ile karşılaşırlar. Sosyal çalışmacıların bu denli cesaret kırıcı durumlar içinde dahi morallerini yüksek tutabilmeleri, kendilerini öfke ve kızgınlık tarafından tüketilmekten uzak tutarak motivasyonlarını yükseltebilmeleri için umut verici bir maneviyat geliştirmeleri gerekmektedir (Sheafor ve Horejsi, 2014, s.52). Bu açıdan geleceğin sosyal çalışmacı adaylarının manevi yönelimlerinin yüksek olması avantaj olarak görülebilir. Elbette bu, bütün sosyal çalışmacıların dindar veya manevi olmalarını/olduğunu gerektirdiği anlamına gelmemekte; aksine, çekilen zorlukların farkındalığı ve dönüşümün olasılığı anlamına gelmektedir (Crisp, 2010, s.26). Eğer sosyal çalışmacı, dinî inanca ve maneviyata müracaatçlardan daha az sahipse yine de saygı ve ilgi ile dinleyerek müracaatçıların inancı veya ritüelleri hakkında bir şeyler öğrenebilir. Bazen de manevi yönelimli bir sosyal çalışmacı kendini manevi tecrübesi olmayan müracaatçllar ile çalışırken bulabilir (Derezotes, 2006). Farklı bölümlerde okuyan üniversite öğrencileriyle yapılan benzer çalışmalarda (Çelik İnce ve Utaş Akhan, 2016; Mert ve Topal, 2018) da öğrencilerin manevi yönelim düzeylerinin yüksek olduğu görülmüştür.

$\mathrm{Bu}$ araştırmada üniversite öğrencilerinin cinsiyetlerine göre manevi yönelim düzeylerinin anlamlı derecede farklı olduğu belirlenmiş ve erkek öğrencilerin manevi yönelim düzeylerine ait puan ortalamalarının, kız öğrencilerin puan ortalamalarından anlamlı derecede daha yüksek olduğu bulunmuştur. Bu durum, erkek öğrencilerin dinî aktivitelerde daha aktif rol almalarından kaynaklanıor olabilir. Nitekim dindarlık ile manevi yönelim 
ilişkisi araştırmanın giriş bölümünde irdelenmiştir. Aydın (2019) da yaptığ çalışmada genç yetişkin erkeklerin maneviyat düzeylerinin kadınların maneviyat düzeylerinden daha yüksek olduğunu tespit etmiş ancak bu farkl1lığın istatistiksel olarak anlamlı olmadığın belirtmiştir. Apak ve Abay'ın (2019) sosyal çalışmacılarla yaptığı alan araştırmasında kadın katılımcıların erkek katılımcilara oranla maneviyata daha mesafeli oldukları tespit edilmiştir. Alanda hem üniversite öğrencileri ile hem de diğer gruplarla yapılan çalışmaların çoğu (Mert ve Topal, 2018; Stewart ve Koeske, 2006) ise bu araştırmada cinsiyet ile ilgili elde edilen sonucu desteklememektedir. Bu araştırmalarda kadınların manevi yönelim düzeyleri erkeklere oranla daha yüksek ve anlamlı bulunmuştur. Bazı araştırmalarda (Doğan, 2006; Yeter, 2019) da manevi yönelim ile cinsiyet arasında anlamlı bir farklılık bulunmamıştır.

Araştırmaya katılan sosyal hizmet bölümü öğrencilerinin sosyal hizmet uygulamasında din ve maneviyatın rolüne ilişkin yüksek puanları, sosyal hizmet uygulamasında din ve maneviyatın önemli bir rolü olduğu görüşüne sahip olduklarını göstermektedir. Sosyal hizmet öğrencileriyle yapılan benzer çalışmalarda (Bhagwan, 2010; Branum, 2005; Graff, 2007; Pandya, 2018; Sheridan ve Amato-Von Hemert, 1999) da öğrenciler sosyal hizmet uygulamasında maneviyatın rolünü önemsediklerini belirtmektedirler. Stewart ve Koeske'nin (2006) sosyal hizmet bölümü öğrencilerinin uygulamada dini ve manevi müdahaleleri kullanma tutumlarına ilişkin yapılan çalışmalarında öğrencilerin çoğu, özellikle dini ve manevi müdahalelerin uygulamada kullanımının uygun olduğunu bildirmişlerdir. Benzer olarak sosyal çalışmacılarla yapılan çalışmalarda (Apak ve Abay, 2019; Derezotes, 1995; Kvarfordt ve Sheridan, 2007) da sosyal hizmet uygulamasinda din ve maneviyatın rolüne yönelik genel olarak olumlu bir tutum sergilendiği ifade edilebilir. Sosyal hizmet eğitimcileri için çıkarılabilecek bir sonuç, sosyal hizmet öğrencilerinin dini/manevi içeriğin sosyal hizmet uygulamalarına dâhil edilmesine ilişkin muhtemel güçlü görüşlerinin farkında olmalarıdır. Ayrıca öğrenciler tarafından bu tür inançların açık bir şekilde tartışılması için güvenli bir sınıf ortamının teşvik edilmesi, bu tür inançların sosyal hizmet uygulamaları için etik standartlar bağlamında ele alınmasını sağlayabilmektedir (Canda ve Furman, 2010).

Sosyal hizmet uygulamasında din ve maneviyatın rolüne bakışta cinsiyet bağlamında anlamlı düzeyde bir farklılığın olmadığı bulgusuna ulaşılmıştır. Cinsiyet değişkeninin sosyal hizmet bölümü öğrencilerinin SHUDMR pu- 
anlarını anlamlı düzeyde etkilemediği görülmektedir. Bu sonuç; yapılan bazı araştırma sonuçları (Graff, 2002) tarafından da desteklenmektedir.

Sosyal hizmet uygulamasında din ve maneviyatın rolüne bakışı etkileyen unsurlardan biri de sosyal hizmet eğitimi sürecinde alınan maneviyatla ilgili derslerdir. Murdock'a (2003) göre üniversitede veya daha sonra böyle bir eğim alanlar, uygulama sürecine gelindiğinde maneviyatı, müdahalelerinde daha fazla kullanmaktadırlar. Araştırma, bu ifade kapsamında gözden geçirildiğinde denilebilir ki; katılımcıların büyük çoğunluğu, bilgi eksikliğinden kaynaklanan bir nedenle maneviyata duyarlı müdahalelerde yeterli donanıma sahip değildir.

Bu nedenle sosyal hizmet öğrencilerine verilen maneviyat ve sosyal hizmet dersini almanın SHUMDR eğilimini artırıp artırmadığını görebilmek için dersi almalarına göre SHUMDR ölçeği puanları arasındaki farka bakılmıştır. Sonuçta, 4 . sınıf öğrencilerinin aynı zamanda maneviyat ve sosyal hizmet dersini almış oldukları göz önünde bulundurulduğunda, bu dersi almış olmanın öğrencilerin SHUDMR düzeylerini yükselttiği ancak bu değişikliğin anlamlı olmadığı görülmektedir. Bu sonuç bazı araştırmalarla (Graff, 2002) paralellik göstermektedir. Yapılan çalışma ile birlikte SHUMDR'ye ilişkin bakışı etkileyen birçok faktör olabileceğini ve sadece okunan sınıfın ve maneviyatla ilgili bir ders almanın tek başına SHUMDR'nin anlamlı bir etkileyicisi olmadığını göstermektedir. Öğrencilerin kişilik yapıları, kişisel maneviyat ve dindarlık düzeyleri, yetiştirilme tarzları ve sosyal çevreleri de birebir SHUMDR düzeyini etkileyebilmektedir. Ayrıca sosyal hizmet eğitimi sürecinde insan hakları, kültüre duyarlılık yaklaşımı, kişinin kendi kaderini tayin etme hakkı gibi sosyal hizmetin temel fikirlerinin manevi yönelime ilişkin olumlu bir tutuma dönüşmesi de söz konusu olabilmektedir.

Manevi yönelim, sosyal hizmet uygulamasında maneviyatın rolünü anlamlı düzeyde açıklamaktadır. Bu sonuca göre sosyal hizmet bölümü öğrencilerinin manevi yönelim düzeyleri arttıkça sosyal hizmet uygulamasında din ve maneviyatın rolüne ilişkin olumlu görüşleri artacaktır. Bu sonuç ile öğrencilerin manevi yönelimleri açısından yüksek puanlar ortaya koyması dinsel ve manevi müdahalelerin sosyal hizmet uygulamalarına dâhil edilmesini onaylama olasılıkları daha yüksek olduğu yönünde olduğu ifade edilebilir. Benzer şekilde, manevi yönelimleri daha az olan öğrencilerin, bu tür uygulamaları kabul etmemelerinin daha muhtemel olduğu keşfedilmiş- 
tir. Alan yazında bu sonucu destekleyen çok sayıda araştırma mevcuttur (Branum, 2005; Graff, 2002; Stewart \& Koeske, 2006). Sheridan ve AmatoVon Hemert (1999), 208 sosyal hizmet bölümü öğrencisiyle yaptıkları çalışmada öğrencilerin din veya maneviyatla güçlü bir bağ hissettiğini ve sosyal hizmet uygulamasında din ve maneviyatın rolünün olumlu olduğu görüşünü bildirmişlerdir. ABD'de 123 mezun sosyal hizmet öğrencisi ile yapılan araştırmada öğrencilerin büyük bir çoğunluğu, sosyal hizmeti tercihinde yani kariyer hayatında maneviyatının veya dini inançlarının etkili olduğunu ifade etmiştir. Malezya'da da benzer bir durum söz konusudur. Malezya gibi öğrencilerin çoğunluğu Müslümanların oluşturduğu farklı bölgelerde dini inanç ve maneviyat, öğrencilerin sosyal hizmet eğitimi almasında uzun zamandan beri önemli ölçüde etkili olmaktadır (Akt: Crisp, 2010).

Sosyal çalışmacılarla yapılan çalışmalarda da manevi yönelimlerinin sosyal hizmet uygulamasında din ve maneviyata duyarlı olmayı etkilediği görülmektedir. Larsen'in (2011) yaptığı çalışma, kişisel maneviyat ve sosyal hizmet uygulaması arasında potansiyel örtüşmeler olduğunu desteklemektedir. Araştırmaya katılanların yarısı, maneviyatlarının sosyal hizmet uygulamasını etkilediğini; yarısına yakını ise yapılan alan çalışmasından maneviyatlarının etkilendiğini ifade etmektedir. Araştırmanın sonucuna göre, dini inancın ve maneviyatın sosyal çalışmacıların özel ve mesleki hayatlarında önemli bir role sahip oldukları görülmektedir. Hodge ve Boddie'ye (2007) göre de dini inanç ve maneviyat, sosyal çalışmacıların özel ve mesleki hayatlarında önemli bir role sahiptir. Ancak sosyal çalışmacılara ait inanç gelenekleri ve manevi motivasyonların; müracaatçı maneviyatlarını nasıl tanımladıkları ile hiçbir ilgisi olmadığını ortaya çıkarmışlardır.

Araştırmada sunulan bulgulardan yola çıkarak, ulaşılan sonuçlar çerçevesinde yapılan öneriler aşağıda belirtilmiştir:

- Sosyal hizmet eğitimi müfredat programlarında maneviyata yönelik ayrıntılı yer verilmesi gerektiği düşünülmektedir.

- Konuyla ilişkili daha büyük örneklem gruplarında ve farklı üniversitelerde okuyan öğrencilerle çalışmalar yapılarak öğrencilerin temelde bu alana yönelik bilgi ve farkındalıklarının belirlenmesi sağlanabilir.

- Bu çalışmada yer verilen değişkenler dişında dini inanç, kültür ve kentsel-kırsal alanda yaşama gibi maneviyat düzeyini etkileyebilecek farklı değişkenlere bakılması önerilebilir. 
- Maneviyat ve sosyal hizmet eğitimi ilişkisine ilişkin sosyal hizmet bölümü akademisyenlerinin görüşlerine dayanarak çeşitli araştırmalar yapilabilir.

- Sosyal hizmet bölümü öğrencilerinin sosyal hizmet uygulamasında din ve maneviyata bakışlarını etkileyen faktörlerin neler olduğuna ilişkin nitel araştırmaların yapılması yararlı bulgular sağlayabilir. 


\title{
EXTENDED ABSTRACT
}

\section{Investigating Relationship Between Role Of Religion And Spirituality İn Social Work Practice And Spiritual Orientation Levels Of The Social Work Students}

\author{
Muhammet Cevat Acar - Hidır Apak \\ Mardin Artuklu University
}

Social work education has a structure that includes both scientific and social features. It can be expressed socially that the profession should be shaped according to the culture and characteristics to which it will be applied. In this case, one of the main tasks of education is to prepare students for a culturally sensitive task that respects differences.

Since spirituality and religion play an important role in all cultures, students who are candidates for social workers need to understand the impact of religion and spirituality on human life. Thus, it will be ensured that students will be informed about the profession they will have in the future and their applicants' religious beliefs and values system (Zastrow and KirstAshman, 2015, p.324). One of the basic principles of social work education is that at this point, it includes different spiritual perspectives and various religious beliefs (Stewart and Koeske, 2006). The term "spirituality" is widely used in the social work literature to include both religious and nonreligious ways in which people develop their framework of meaning, purpose and morality (Canda and Furman, 2010; Vetvik, Danbolt, Furman, Benson and Canda, 2018). In addition, spirituality is a concept associated with empowerment, ecosystem, cultural sensitivity and holistic approach, which are frequently used in social work practices (Tatlıcıoğlu and Kılıç, 2019).

This research was carried out with the relational screening model, which is one of the quantitative research methods. Relational scanning model is a model used to determine the presence and degree of the change between 
two or more variables. Correlation analysis is mostly used in this model (Karasar, 2010, p.81).

The universe of this research is 373 people who are 3rd and 4th year students studying at the Social Work Department of Bingöl University in 20182019 spring semester. In the research, it was tried to reach all the students who volunteered to participate in the questionnaire from the students studying at Bingöl University Social Service Department by not choosing a sample. The sample of the research was determined by using nonprobability sampling method since it is the goal of reaching the whole universe. The sample of the study consists of 242 students from 373 students (women $=106$, men $=136$ ).

Spiritual Orientation Scale (SOC): It was used to analyze the spiritual orientation of students developed by Kasapoğlu (2015). The scale consists of one-dimensional likert type and 16 items. The high score obtained from the scale indicates that the spiritual orientation is high. Explanatory and confirmatory factor analysis techniques were used for the construct validity studies in the scale. To evaluate the reliability of the scale, the Cronbach Alpha reliability coefficient was calculated and the test-retest reliability coefficient was found to be .84 . In this study, the Cronbach Alpha value of the spiritual orientation scale was found to be .97 .

The Role of Religion and Spirituality in Social Work Practice (SHUDMR) Scale: Developed by Sheridan (2000), this scale was adapted to Turkish by Apak (2018b). The aim of the scale is to determine the opinions of the participants about the role of religion or spirituality in social work practice. The scale consists of one-point Likert type and 13 items. In the scale development process, exploratory and confirmatory factor analysis studies were conducted. Cronbach Alpha coefficient of the scale was calculated as .82. In this study, Cronbach Alpha value of SHUDMR Scale was calculated as .91.

When the spiritual orientation levels of the social service students are examined, it can be said that the spiritual orientation levels of the students are quite high. This finding is in line with many studies (Bhagwan, 2010; Kaplan and Dziegielewski, 1999; Stewart and Koeske, 2006).

In spirituality, social work practice; it can be an argument that motivates social workers and enables them to cope with difficulties. Social workers face almost every day disadvantaged individuals suffering from injustice, discrimination and violence. Social workers need to develop a promising 
spirituality to keep their morale high even in such discouraging situations and to increase their motivation by keeping themselves away from being consumed by anger and anger (Sheafor and Horejsi, 2014, p. 52). In this respect, the high spiritual orientation of future social worker candidates can be seen as an advantage.

In this study, it was determined that the spiritual orientation levels of university students were significantly different according to their genders and it was found that the mean scores of male students' spiritual orientation levels were significantly higher than the average scores of female students. This may be due to the fact that male students take a more active role in religious activities. As a matter of fact, the relationship between religiousness and spiritual orientation is examined in the introduction part of the research in Aydin (2019).

\section{Kaynakça / References}

Ağırbaş, F. (2017). Manevi yönelimli aile danışmanlı̆̆ı. Yayımlanmamış Yüksek lisans Tezi. İstanbul: Marmara Üniversitesi Sosyal Bilimler Enstitüsü.

Apak, H. (2018a). Sosyal hizmet ve maneviyat. İstanbul: Bir Yayıncllk.

Apak, H. (2018b). Sosyal hizmet uygulamasında din ve maneviyatın rolü (SHUDMR) ölçeğinin Türkçeye uyarlanması: Güvenirlik ve geçerlik çalı̧̧ması. İnsan ve Toplum Bilimleri Araştırmaları Dergisi, 7(3), 1889-1903.

Apak, H. ve Abay, A. R. (2019). Sosyal hizmet ve maneviyat: Sosyal çalışmacılar üzerine bir alan araştırması. Toplum ve Sosyal Hizmet, 30(1), 56-87.

Aydın, M. (2019). Genç yetişkinlerde mutluluk, maneviyat ve kanaat. The Journal of Social Sciences, 6 (3), 439-448.

Bethel (2004). Impact of social work spirituality courses on student attitudes, values, and spiritual wellness. Journal of Religion \& Spirituality in Social Work: Social Thought, 23(4), 27-45.

Bhagwan R. (2010). Spirituality in social work: A survey of students at South African Universities. Social Work Education: The International Journal, 29(2), 188204.

Branum, S. N. (2005). An evaluation of religion and spirituality in social work education. A dissertation submitted in partial fulfillment of the degree master of science in Social Work. Graduate School of The University of Texas at Arlington.

Canda, E. R. (1999). Spiritually sensitive social work: Key concepts and ideals. Journal of Social Work Theory and Practice. 1(1), 1-15. 
Canda, E. R. ve Furman L. D. (2010). Spiritual diversity in social work practice. 2nd ed. New York: Oxford University Press.

Crisp, B. R. (2010). Spirituality and social work-contemporary social work. New York: Ashgate Publisher.

Çağlar, T. (2012). Türkiye'de sosyal hizmet disiplini üzerine bir derleme. İ. Cılga ve B. Hatiboğlu (Eds) içinde, Sosyal bilimler ve sosyal hizmet üzerine düşünceler. Ankara: SABEV Yayınları.

Çelik İnce, S. ve Utaş Akhan, L. (2016). Öğrenci hemşirelerin maneviyat ve manevi bakıma ilişkin algıları. Hemşirelikte Eğitim ve Araştırma Dergisi, 13(3), 202-208.

Derezotes, D.S. (1995). Spirituality and religiosity: Neglected factors in social work practice. Arte, 20(1), 1-15.

Derezotes, D. S. (2006). Spiritually oriented social work practice. Boston, MA: Pearson.

Doğan, T. (2006). Üniversite öğrencilerinin iyilik halinin "maneviyat" ve "serbest zaman" boyutlarının incelenmesi. Türk Psikolojik Danışına ve Rehberlik Dergisi, 3(26), 1-16.

Dudley, J. R., ve Helfgott, C. (1990). Exploring a place for spirituality in the social work curriculum. Journal of Social Work Education, 26, 287-294.

Ekşi, H. ve Kaya, Ç. (2016). Manevi yönelimli psikoterapi ve psikolojik danışma. İstanbul: Kaknüs Yayınları.

Ekşi, H., Kaya, Ç. ve Çiftçi, M. (2016) Maneviyat ve psikolojik danışma. Halil Ekşi ve Çınar Kaya (Ed.), Manevi Yönelimli Psikoterapi ve Psikolojik Danışma (s. 13-28) içinde. İstanbul: Kaknüs Yayınları.

Gilligan, P. ve Furness, S. (2005). The role of religion and spirituality in social work practice: Views and experiences of social workers and students. British Journal of Social Work, 36(4), 617-637.

Graff, D. L. (2002). Beliefs or not: A study of bachelor of social work students' beliefs about the inclusion of religious and spiritual content in social work. A dissertation submitted in partial fulfillment of the degree of Doctor of Philosophy. Graduate School of The University of Texas at Austin.

Graff, D. (2007). A study of baccalaureate social work students' beliefs about the inclusion of religious and spiritual content in social work. Journal of Social Work Education, 43(2), 243-256.

Hodge, D., ve Boddie, S. C. (2007). Social workers' personal spiritual characteristics and their conceptualizations of spirituality and religion: A mixed method study. Journal of Religion and Spirituality in Social Work, 26(1),53-70. 
Kane, M. N., ve Jacobs, R. J. (2010) Predictors of the importance of spiritual and religious beliefs among university students. Journal of Religion $\mathcal{E}$ Spirituality in Social Work: Social Thought, 29(1), 49-70.

Kaplan, A., ve Dziegielewski, S. (1999). Graduate social work students' attitudes and behaviors toward spirituality and religion: Issues for education and practice. Social Work and Christianity, 26(1), 25-39.

Karasar, N. (2010). Bilimsel araştırma yöntemi: Kavramlar-ilkeler-teknikler. Ankara: Nobel Yayın Dağıtım.

Kasapoğlu, F. (2015). Manevi Yönelim Ölçeği'nin geliştirilmesi: Geçerlik ve güvenirlik çalışması. İnönü Üniversitesi Ĕ̆itim Fakültesi Dergisi, 16(3), 51-68.

Kesgin, H. (2019). Manevi destek hizmetleri ve Diyanet İşleri Başkanlığı. International Social Sciences Studies Journal, 5(30), 557-571.

Kut, S. (1991). Türkiye'de sosyal hizmet eğitimi. R. Keleş, J. Nowak ve İ. Tomanbay (Eds) içinde, Türkiye'de ve Almanya'da sosyal hizmetler ansiklopedik sözlük (ss.205-208). Ankara: Selvi Yayınları.

Kvarfordt, C. L., ve Sheridan, M. J. (2007). The role of religion and spirituality in working with children and adolescents. Journal of Religion $\mathcal{E}$ Spirituality in Social Work: Social Thought, 26(3), 1-23.

Larsen, K. M. (2011). How spiritual are social workers? An exploration of social work practitioners' personal spiritual beliefs, attitudes, and practices. Journal of Religion E Spirituality in Social Work: Social Thought, 30(1), 17-33.

Lee, E. O. ve Barrett, C. (2007). Integrating spirituality, faith, and social justice in social work practice and education: A pilot study. Journal of Religion $\mathcal{E}$ Spirituality in Social Work: Social Thought, 26(2), 1-21.

Martin, M W. (2007). Happiness and virtue in positive psychology. Journal for the Theory of Social Behaviour, 37(1), 89-103.

Mert, A., ve Topal, T. (2018). Benlik ayrımlaşmasının manevi yönelimine etkisinin bazı değişkenlerle incelenmesi. OPUS-Uluslararası Toplum Araştırmalarn Dergisi, 8(14), 68-91.

Murdock, V. (2003) Religion and spirituality in gerontological social work practice. A dissertation submitted in partial fulfillment of the degree of Doctor of Philosophy. College of Social Work University of South Carolina.

Özdoğan, Ö. (2007). İsimsiz hayatlar: Manevi ve psikolojik yaklaşımla arınma ve öze dönüş. Ankara: Lotus Yayınevi.

Pandya, S. P. (2018). Students' views on expanding contours of social work practice through spirituality. Journal of Religion $\mathcal{E}$ Spirituality in Social Work: Social Thought, 37(3), 302-322. 
Peterson, C. ve Seligman, M. (2004). Character strengths and virtues: A handbook and classification. New York: Oxford University Press.

Prior, M. K. ve Quinn, A. S. (2012). The Relationship between spirituality and social justice advocacy: attitudes of social work students. Journal of Religion E Spirituality in Social Work: Social Thought, 31(1-2), 172-192.

Richards, P.S. ve Bergin, A.E. (2011). A spiritual strategy for counseling and psychotherapy. Washington, DC: American Psychological Association.

Rinkel, M., Larsen, K., Harrington, C., ve Chun, C. (2018). Effects of social work practice on practitioners' spirituality. Journal of Religion $\mathcal{E}$ Spirituality in Social Work: Social Thought, 37(4), 331-350.

Seinfeld, J. (2012). Spirituality in social work practice. Clinical Social Work Journal, 40(2), 240-244.

Sheafor, B. W. ve Horejsi, C. J. (2014). Sosyal hizmet uygulaması temel teknikler ve ilkeler. Ankara: Nika Yayınları.

Sheridan, M. J. ve Amato-von Hemert, K. (1999). The role of religion and spirituality in social work education and practice: A survey of student views and experiences. Journal of Social Work Education, 35(1), 125-141.

Sheridan, M. J., Wilmer, C. M., ve Atcheson. L. (1994). Inclusion of content on religion and spirituality in the social work curriculum: A study of faculty views. Journal of Social Work Education, 30(3), 363-376.

Sperry, L. ve Shafranske, E. P. (2009). Spiritually oriented psychotherapy. Washington, DC: American Psychological Association.

Streets, F. (2009). Overcoming a fear of religion in social work education and practice. Journal of Religion \& Spirituality in Social Work: Social Thought, 28(1-2), 185-199.

Stewart, C. ve Koeske, G. (2006) Social work students' attitudes concerning the use of religious and spiritual interventions in social work practice. Journal of Teaching in Social Work, 26(1-2), 31-49.

Tatlıcıoğlu, O. ve Kılıç, A. (2019). Klinik sosyal hizmette tinsellik. Ö. Altındağ, O. Tatlıcıoğlu ve Y. Kryvenko (Ed.) içinde Current Problems and Approaches in Social Work (s. 65-72). London: IJOPEC.

Vetvik, E., Danbolt, T., Furman, L. D., Benson, P. W. ve Canda, E. R. (2018). A comparative analysis of Norwegian and American social workers' views about inclusion of religion and spirituality in social work. Journal of Religion E Spirituality in Social Work: Social Thought, 37(2), 105-127. 
Wagler-Martin, W. (2007). Listening to our stillness: Giving voice to our spirituality (spirituality and clinical practice). Coates, J., J. R. Graham, B. Swartzentruber and B. Ouellette (Ed.), Spirituality and social work: Selected Canadian readings içinde (s.135-142). Toronto: Canadian Scholars' Press.

Yeşilkayalı, E. (2018). Sosyal çalışma uygulamalarında manevi değerlendirmenin yeri ve önemi: David R. Hodge'ın çalışmaları çerçevesinde genel bir bakış. Tarih Okulu Dergisi, 11(XXXVI), 88-103.

Yeter, S. İ. (2019). Üniversite öğrencilerinin mutluluk düzeylerinin aile aidiyeti ve manevi yönelimlerine göre yordanması. Yayımlanmamış Yüksek Lisans Tezi. İstanbul: Marmara Üniversitesi Eğitim Bilimleri Enstitüsü.

Zastrow, C. (2013). Sosyal hizmete giriş. Ankara: Nika Yayınları.

\section{Kaynakça Bilgisi / Citation Information}

Acar, M.C. ve Apak, H. (2020). Sosyal hizmet uygulamasinda din ve maneviyatın rolü ile manevi yönelim arasındaki ilişkinin incelenmesi. OPUS-Uluslararası Toplum Araştırmaları Dergisi, 15(24), 2505-2527. DOI: 10.26466/opus.658418 